without the use of alcohol. I cannot believe that diffusible stimulants, such as ammonium carbonate or any preparation of ether, can therapeutically take the place of a well-matured spirit, whether given as alcohol or wine. In my own practice I have been accustomed to use alcoholic remedies with a free hand. Unless I am absolutely incompetent to form a correct judgment on such a matter, I feel convinced of their efficacy. I do not believe in routine administration; our hospital method is pernicious and undoubtedly leads to much abuse and waste. A physician visits his patients but twice a week and orders stimulants, orders them for the immediate occasion, and but rarely intends the remedy to be continued de die in diem, as we find is so usually the case. The administration of alcohol to some patients is one of the most important points in the entire treatment of the case; the dose may, and generally does, require constant alteration. A very severe case of fever under my care a few months ago was complicated with the most extreme irritability of tendons. I had never before seen such incessant and general muscular spasms. The note on the case taken by the medical attendant states: "Subsultus universal ; almost every tendon jerking ; well marked in erector spinæ." The patient was a woman past forty years of age, of very abstemious habits. During the stage of muscular spasm brandy was largely made use of-half an ounce every hour, with an occasional extra dose. The remedy acted like a charm, giving intervals of rest from this most distressing and painful complication. Although the amount of stimulant taken was very large, no untoward symptoms followed its free exhibition. Surely if the remedy had been harmful there would have been some symptom denoting its baneful action. The following is a striking instance of the beneficial result following a large dose of alcohol. A girl seventeen years of age, suffering from a rather severe attack of fever, in which the temperature ranged high on the afternoon of the twenty-first day of illness, became more feverish, the pyrexia being accompanied by delirium. I happened to be away from London, and the patient was seen in my absence by another physician, who found the temperature to be $105^{\circ} \mathrm{F}$. He ordered a wet pack. When I saw the patient she had been in the pack twenty minutes, and the temperature in the axilla was $1052^{\circ}$. The feet, hands, ears, and nose were cold to the touch; the pulse was almost imperceptible at the wrist. The patient during her rambling delirium complained of feeling "so cold." I gave an unmeasured quantity of brandy (presumably about four ounces), removed the pack, and placed hot-water bottles to the feet. Within a short time the temperature was lowered, the patient falling into a gentle sleep, from which she awoke free from delirium on the following morning, the temperature being $99^{\circ}$.

Having regard to the use of alcohol in the general treatment of disease, there is, as you are all probably well aware, what we may well call a gigantic experiment carried on in our midst. A hospital exists in London for the treatment of all classes of disease without the use of any form of alcoholic stimulant. Turning to the official record emanating from this institution, I find that during the years 1886, 1887, and 1888 there were 35 cases of enteric fever under treatment, with a mortality of 29 per cent., ten patients falling victims. During the years 1889, 1890, and 1891, 25 cases were received, with five deaths, or a mortality of 20 per cent. The London Temperance Hospital is within a short distance of the North-West London Hospital, to which I was attached as sole physician. During this period there were 39 patients under my treatment, four cases proving fatal ; these fatal cases have been already referred to. Now, both bospitals serve the same district; the patients belong to the same class, and the comparison between the two death-rates is as fair and reasonable as any such comparison is possible to be. In the one institution alcohol was administered as required, often in large quantities; in the other no such remedy was made use of. With the data at my command I cannot but feel that with regard to the treatment of typhoid fever at the London Temperance Hospital patients do not receive that help which the experience of by far the largest majority of physicians would dictate as being essential for success. Since writing these lines Sir William Jenner's valuable lectures and addresses have been placed in the bands of the profession; and with regard to the use of alcohol in typhoid fever the opinion of that learned physician ranks as high as, if not higher than, any other that can be quoted. He writes:

"I may sum up my experience in regard to the use of alcohol in the treatment of typhoid fever thus : its influence is exerted primarily on the nervous system, and through it on the several

organs and processes-for example, the heart and generall nutritive processes--changes on which the rise and fall of temperature depend. In judiciously selected cases it lowere temperature, increases the force, and diminishes the frequercy of the heart-beats; it calms and soothes the patient, diminishes the tremor and quiets delirium, and induces sleep ...... it is in exceptional cases only that more than twelve ounces of brandy in the twenty-four hours can be taken witheut inducing some of the worst symptoms of prostration. Nearly all the good effects of alcohol where it is indicated are obtained by four, six, or eight onnces of brandy in twentyfour hours. ...... Alcothol by the influence it exerts on the nervous system is of the greatest value in the treatment of typhoid fever." (The italics are mine.) Such, then, is the matured weighty opinion of the highest possible authority. And yet we have a hospital in our midst asserting that it possesses means and remedies which, if not superior, are equal in efficiency to the proscribed drug, alcohol. Doubtless the institution shelters itself under what may be called an urgency order-namely, that alcohol, if ordered by the medical officer, can be obtained for any patient on entering the particulars of the case in a book kept specially for that purpose. During the six years of which the official reports lie before me, and to which period I have already referred, in no single instance in connexion with the sixty patients under treatment for typhoid fever was a dase alcohol considered beneficial.

\title{
RODENT CANCER AND ITS TREATMENT BY ELECTRICITY; WITH CASES.
}

\section{By J. INGLIS.PARSONS, M.D. DURF., M.R.C.P. LONo. \&c.}

ThIs disease, better known as rodent ulcer, is one of the forms of malignant disease closely resembling epithelioma in its minute structure. A glance at Fig. 1, taken from Case 4, shows the typical bird's-nest cell almost characteristic of that disease. In other parts (Fig. 2), however, the resemblance is not so strong. The epithelial cells are very numerous, but they are not so large. In places they are imbedded in an almost structureless matrix and present some what the appearance of a round-celled sarcoma. Occasionally the cells are aggregated into columns and separated by $\varepsilon$

FIG. 1.

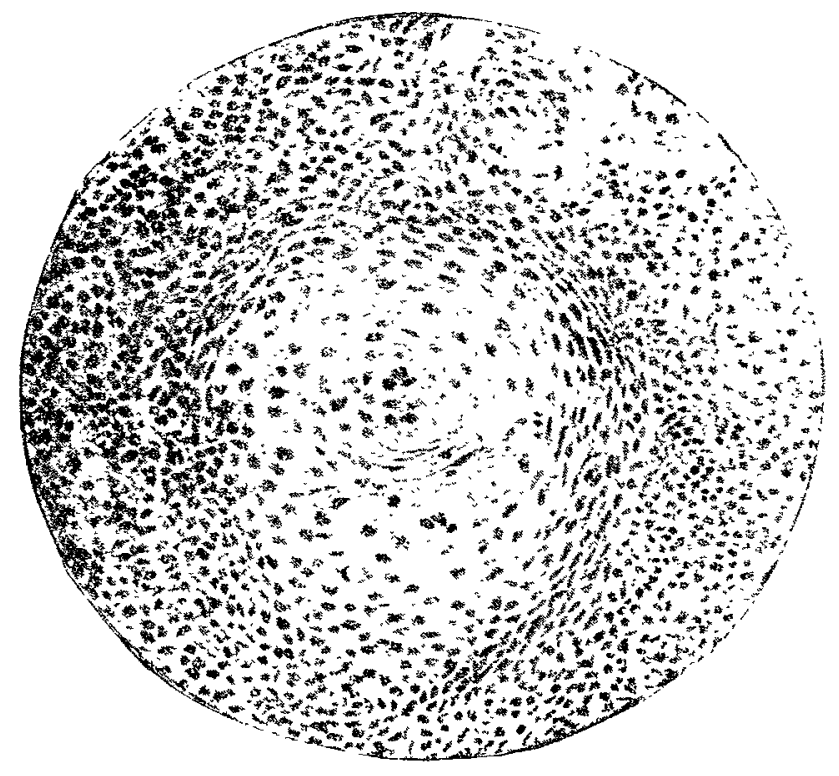

delicate connective tissue. The stroma never presents exuberant growth of connective tissue round in a true infective epithelioma. Rodent cancer, like other forms of malignant disease, infiltrates and destroys every heal thy structure that it comes into contact with. Skin, muscles, cartilage, and bone all disappear before it, although it does not infect the lymphatics or the system at large; and notwithstanding that its progress is slower than that of other forms of carcinoma, it is a very serious disease, and its gravity is not sufficient expressed by the term "rodent ulcer." Sir James Paget, in 
his article in "Holmes's System of Surgery," wrote as follows: "It is possible now to class rodent ulcers among the eancerous. This being so, it secms scarcely necessarv still to call them rodent ulcers; probably the term will gradually cease to ie employed." Mr. C. H. Moore first used the term "rodent cancer," as the title of his book published in 1867. The infiltration which takes place into the healthy tissues is nothing like so great as in ordinary carcinoma. At the edges, where the growth is most recent, it is least, while the centre, where it is of long standing, it is greatest. This fact has to be borne in mind during an operation, so as to avoid as much destruction as possible consistent with eradication. Like other carcinomata, it usually attacks persons past the middle age. Both sexes appear to be equally Lable. The lymphatic glands are never infected. Occacionally they may be found to be enlarged, but this is always iue to an inflammatory condition and will subside under appropriate treatment. The progress of the disease is slow. The genera! health is not disturbed for some years until the qlcer has attained a large size. Pain is nearly always conspicuous by its absence. It is only in advanced cases, when

FIG. 2.

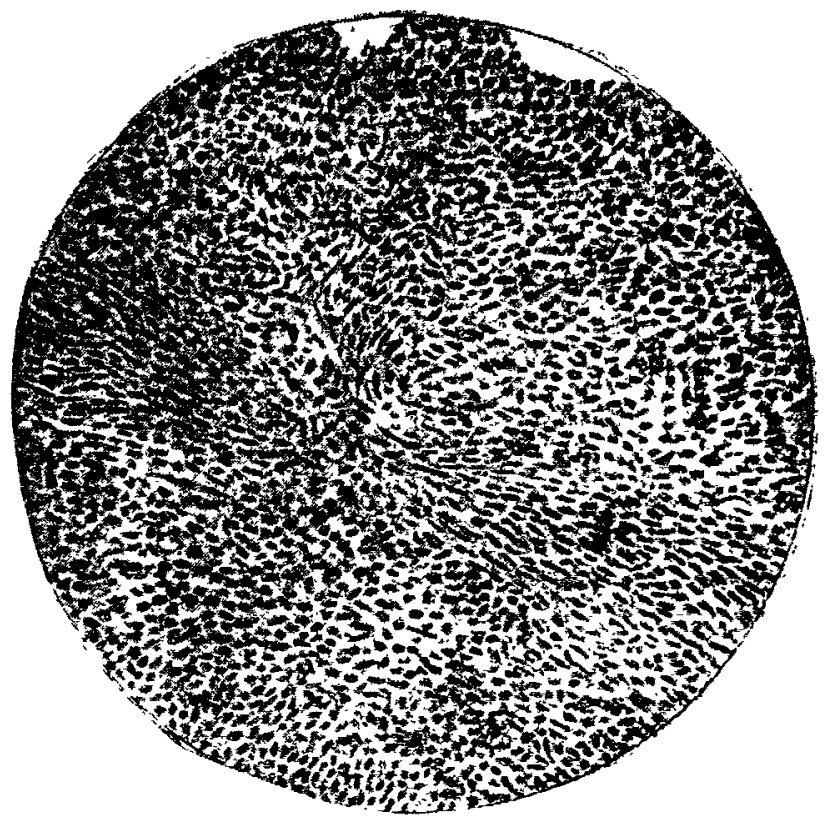

There is a constant sischarge from a large surface, that the geueral health sufiers. Pain also may then be present if a karge nerve trunk becomes involved.

The appearance of the ulcer is characteristic. It is nearly always situated on the face, between the nose and the eye. The base is of a dull red colour, glazed, and devoid of granuגations, $O$ covered by a dark scab of dried secretion. The edges are well defined, having a dentated outline and usually a slightly raised border when the ulceration has kept pace with the growth. In a veglected case it is not uncommon to nnd a thick boundary of new growth at some parts. The dge of the ulcer then presents at thick, well raised margin, which is rathervascular, semi-elastic, and somewhat translucent in appearence.

The diagnosis is not difficult if all the factors of the case are considered. The age of the patient, the position of the disease, the slow progress, absence of pain and lymphatic enlargemext. and the appearance of the ulcer form a group of xymptoms that serve to distinguish it from lupus, syphilis, and infective carcinoma.

When death occurs in an untreated case it is usually from exhaustion or bæmorrhage. The disease is more fatal in the meck because important structures are sooner involved. Aceording to Moore the duration of life may not exceed five years frcm the commencement of the disease, but it may axterd to twenty.

As to treatment, $t, w^{\prime}$ ) methods have found favour with argeons: excision by the knife, and destruction by caustics. Both of these are eflicacious in some cases, but both have disalvantages. When the growth is excised profuse hæmorrhage takes place. This not only weakens the patient, but renders it extremely difficult for the operator to see what be is about and to know the exact limits of the disease. Any unnecessary destructior of tissue is to be strongly deprecated on account -f arbsequent deformity of the face. Caustics are difficult to anpiy; they take some hours to eat through the diseased structures, and during this time the patient suffers intolerable pain. The amount of destruction cannot be regulated with any nicety. Electricity is free from both these draw. backs and has other advantages. The electrolytic action prevents any bæmorrhage, so that the operator is able to see exactly how far he has gove and to avoid any unnecessary destruction of tissue. There is no pain after the electrical application; in fact, for some days after-sensation is quite abolished. The amount of destruction can be regulated with the greatest nicety by increasing or diminishing the strength of the current. The cicatrix which follows appears to leave less deformity than when other means have been employed (Diagrams 1 and 2). For an ordinary case one application under an anæsthetic is sufficient, but with a large ulcer two or three may be necessary. Two needles are employed, with a current strength of 200 to 400 milliampères. The caustic action of both poles is freely used, and the current is constantly alternated with a hand commutator. There is no danger in a current of this strength if care is used. (The patient in case 2 was eighty-five years of age and underwent the operation without a bad symptom ) There is no shock afterwards, and the patient can even get up the next day in many instances. No rise of temperature takes place if the wound is kept aseptic. The sloughs separate in the course of a week or ten days, and the ulcer soon heals, leaving a firm cicatrix. Skin grafting is sometimes required. If at any future time a suspiciouslooking spot should appear, a short application lasting five or ten minutes will dispose of it. In any case a year or two of immunity can be promised even with a difficult subject. Case 2 has gone nearly two years without recurrence, and that after only one application. Case 1 went eighteen months without recurrence, and Case 4 has kept well for the same period since the operation. All these were advanced and difficult cases that had undergone every kind of treatment.

CASE 1 -The patient, who was aged seventy-one, was sent to me by Dr. Wm. Anderson of Richmond, Surrey. The disease first began sixteen years previously on the side of the nose, ulceration following. Caustics were applied on several occasions, and the part was once completely excised with the knife. In June, 1891, there was a deep excavated ulcer extending from the inner canthus of the right eye to the nose. The edges were slightly raised, with a dentated margin. The base was of a dull red colour, smooth and glazed. On July 25th one application of electricity was made under the A.C.E. mixture. The patient made a quick recovery, and the ulcer was completely healed a month later, without any deformity to the face. The patient remained well until April, 1893, when a small ulcer again appeared and, Dr. Gardiner assisting, a second application was made under the A.C.E. mixture. This again healed quickly. In August, 1893, the patient was perfectly well ; not a trace of disease could be seen. The cicatrix was small, firm, and healthy.

CAst 2. -The patient, who was aged eighty-five, was likewise brought to me in consultation by $\mathrm{Dr}$. Wm. Anderson. The disease commenced nine years previously. Caustics were applied on several occasions, but without much benefit. 'l'he part was then completely excised, On June 16th, 1891, there was an ulcer involving the conjunctiva and both eyelids of the left eye, extending on to the nose and down to the periosteum. Vision in the left eye was lost. I declined to operate, but the patient, who was a friend of the one referred to in Case 1, insisted. Mr. Makins was called in and excised the left eyeball on Sept. 7th. On the 25 th electricity was applied under the A.C.E. mixture, and the ulcer and growth were destroyed. The wound healed complet ely in a month's time. In June, 1893, I saw Dr. Gardiner (Dr. Anderson's partner), and he informed me that the patient had had no recurrence.

CASE 3 - The patient, aged forty-eight, was sent to me by Dr. Wm. Anderson in November, 1891. Ten years previously the disease first appeared at the junction of the right ala of the nose and upper lip. The part had been scraped and caustics applied on several occasions without much benefit. It was then completely excised with the knife. There was now a large irregular ulcer extending on to the cheek and involving the nose and upper lip. The disease had crept up the mucous membrane of the right nostril for some distance and had partially destroyed the right ala. The upper lip was drawn up, and only a thin septum remained. On Dec. 2nd, under chloroform, the whole of the growth was destroyed by means of electricity. There was great difficulty in reaching the disease within the nostril. In the course of six weeks the ulcer was completely healed. In November, 1892, a small 
DIAGRAM 1.

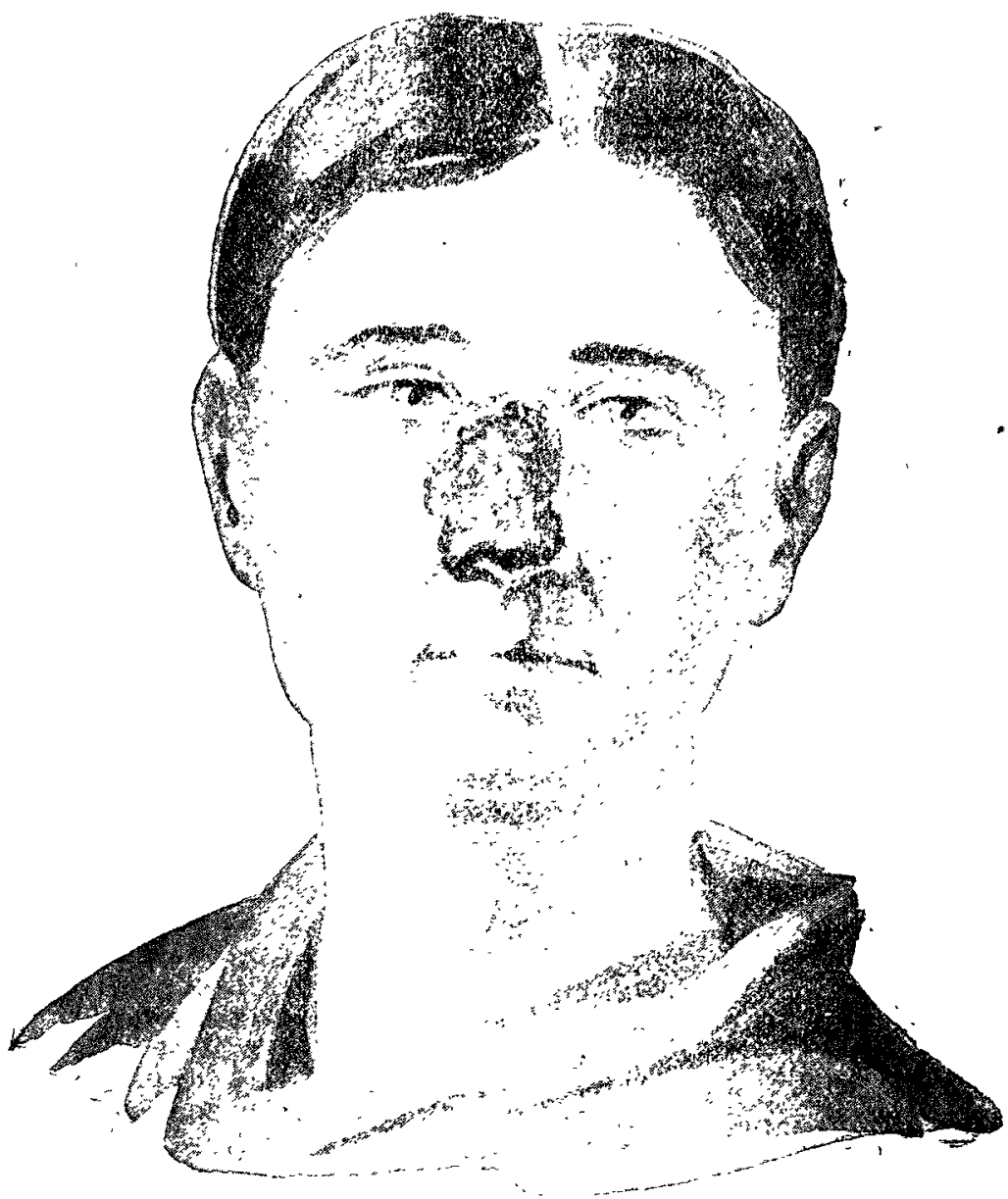

Diacirais 2.

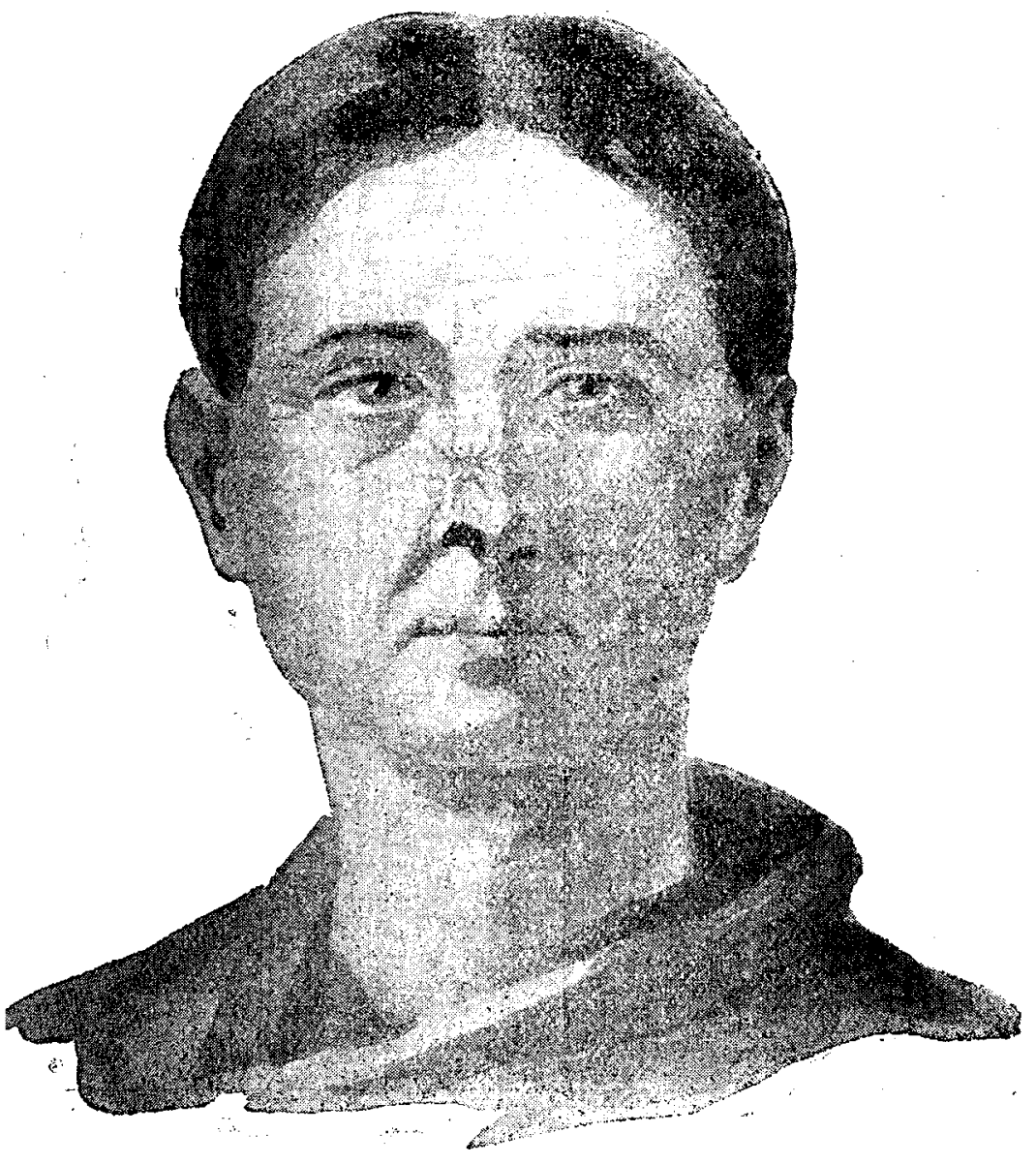

spot again appeared on the lip. She came to town and remained for one night. A short application for ten minutes was made, and the spot healed. In March, 1893, an ulcer appeared in the right nostril. This was destroyed in ome application and soon healed.

CAsk 4. - The patient, aged fifty-three, was under the care of Sir Francis Laking. Fourteen years ago the disease commenced on the right side of the nose. The part had bee scraped and caustics applied. Healing followed for a time, but the ulcer recurred. It was then excised, but again recurred. Later on excision was twice performed without good results. Hom coopathic and other treatment was tried. In April, 1892, I found a large excavated ulcer covering the whole of the nose and extending up to the mucous membrane of the right eye. The disease had penetrated the nasal cartilages and the left nasal bone. The upper and lower margine presented a thick raised border. Diagram 1 shows the appearance of the face before operation. Figs. 1 and 2 show the minute structure of the growth. The general health in this instance was impaired by the extent of the disease and nervous depression. On account of the difficulties of the case three applications of electricity were necessary. The left nasal bone had to be destroyed as well as a superficial layer of cartilage. Great care was necessary in order to destroy the disease and yet leave enough tissue to preserve the symmetry of the nose. On account of the large size of the vlcer and the absence of connective tissue, healing was slower than in the other cases. Numerous skin grafts were applied. At the end of three months the wound healed and presented a cicatrix one-fourth the size of the originat ulcer. (Diagram 2.) In September, 1893, eighteen months after treatment, the patient had kept well, had gained in weight and strength, and could join in all the duties anc pleasures of life.

Queen-street, Mayfair, $\mathbf{w}$.

\section{THYROID SECRETION AS A FACTOR IX EXOPHTHALMIC GOITRE.}

By GEORGE R. MURRAY, B.A., M.B. CANTAB., iM.R.C.P. LOND.,

PROFESSOR OF COMPARATIVE PATHOLOGY IN THE UNIVERSITY OF DURHAM ; PATHOLOGIST TO IHE HOSPITAL FOR SICK CHILDREN, NEWCASTLE-ON-TYNE.

MUCH has been written about exophthalmic goitre, but is many of the papers which have been published on this disease little attention has been paid to the part which the enlarged thyroid gland itself may play in the production of some of the symptoms which are usually present. Möbius has written in support of the theory that there is a toxæmia produced by the enlarged thyroid gland. Müller ${ }^{1}$ maintains that, though the altered thyroid gland is a secondary factor in Graves" disease, it plays an important part in the production of the symptoms. Wette ${ }^{2}$ considers that the goitre is the principal cause of the disease. He attributes the exophthalmos and palpitations to the pressure of the enlarged thyroid gland npon the sympathetic nerve, and the variable nervous symptoms to "a general intoxication due to the products which the diseased thyroid gland secretes." $\mathrm{Mr}$. Arthur Maude, ${ }^{3}$ in $\mathbf{2}$ paper read at the opening meeting of the Medical Society of London this year, brought forward some valuable evidence to show that the symptoms of exophthalmic goitre may be due to a general nerve poison, probably to be found in the thyroid gland. The evidence possessed at present does not justify the supposition that the thyroid gland is the primary factor in exophthalmic goitre, but I wish to draw attention to a few facts which, when taken together, do indicate that some of the symptoms may be due to the absorption of an excessive or: possibly altered secretion from that gland.

There is now strong evidence that the thyroid gland is $\%$ secretory gland-ductless, it is true; but it has been shown by King, ${ }^{4}$ Baber and other observers that the secretion passer along the lymphatics into the general circulation, and so is distributed all over the body. The effects of atrophy or removal of the thyroid gland in man and in many of the lower

1 Dentsches Archiv für Klinische Medicin, li., 4 und 5. 2 Archiv für Klinische Cuirurgie, xliv., 3 . 3 THE LANCET, Oct. 31st, 1893

4 Professor Victor Horsley: Remarks on the Function of the Thyreid Gland, Brit. Med. Jour., Jan. 30th, 1892. 